\title{
TÉCNICA DE DESCELULARIZAÇÃO DE PULMÕES PARA A BIOENGENHARIA DE ÓRGÃOS
}

\author{
Leticia Lopes Guimarães ${ }^{1}$ \\ Jessica Julioti Urbano ${ }^{2}$ \\ Renata Kelly da Palma ${ }^{3}$ \\ Henrique Pichioli ${ }^{4}$ \\ Murilo Brandimarte ${ }^{5}$ \\ Vinicius Calbianco Queiroz ${ }^{6}$ \\ Daniel Navajas ${ }^{7}$ \\ Ramon Farre ${ }^{8}$ \\ Luis Vicente Franco de Oliveira ${ }^{9}$
}

Resumo: As principais doenças do sistema respiratório, tais como a obstrução pulmonar crônica, o enfisema pulmonar, a fibrose pulmonar idiopática e a hipertensão arterial pulmonar primária, tem como resultado um dano estrutural no parênquima pulmonar irreversível, sendo o transplante pulmonar a única indicação terapêutica. Infelizmente, o sucesso do transplante pulmonar é limitado, principalmente devido à escassez do número de doadores de órgãos e incidência de bronquiolite obliterante o que resulta em uma resposta aloimune provocada pelas disparidades entre o doador e os antígenos do receptor. Neste contexto, a bioengenharia de pulmões é considerada uma alternativa terapêutica em potencial. Este estudo visa demonstrar em um modelo experimental animal o processo de descelularização de pulmões visando a preparação de scaffolds para a recriação artificial de órgãos. A matriz de órgãos descelularizados, potencialmente, mantém a arquitetura tridimensional e a composição bioquímica, bem como a microvasculatura do tecido original. Esta capacidade torna o pulmão descelularizado promissor para a geração bioartificial de pulmões funcionais.

Palavras-chave: Descelularização; Pulmões, Bioengenharia de órgãos, Engenharia Biomédica.

\footnotetext{
1 Programa de mestrado e doutorado em Ciências da Reabilitação, Universidade Nove de Julho (UNINOVE), São Paulo (SP), Brasil. E-mail: letticialopes2@bol.com.br.

${ }^{2}$ Programa de mestrado e doutorado em Ciências da Reabilitação, Universidade Nove de Julho (UNINOVE), São Paulo (SP), Brasil. E-mail: jejuliotiurbano@gmail.com.

${ }^{3}$ Programa de mestrado e doutorado em Ciências da Reabilitação, Universidade Nove de Julho (UNINOVE), São Paulo (SP), Brasil. E-mail: rekellyp@hotmail.com.

${ }^{4}$ Programa de mestrado e doutorado em Ciências da Reabilitação, Universidade Nove de Julho (UNINOVE), São Paulo (SP), Brasil. E-mail: hpichioli@gmail.com.

${ }_{5}^{5}$ Programa de mestrado e doutorado em Ciências da Reabilitação, Universidade Nove de Julho (UNINOVE), São Paulo (SP), Brasil. E-mail: brandimartemurilo@gmail.com.

${ }^{6}$ Programa de mestrado e doutorado em Ciências da Reabilitação, Universidade Nove de Julho (UNINOVE), São Paulo (SP), Brasil. E-mail: viniciuscqueiroz29@hotmail.com.

${ }^{7}$ Facultat de Medicina, Universitat de Barcelona, Barcelona, Espanha. E-mail: leleticialopes2@gmail.com.

${ }^{8}$ Facultat de Medicina, Universitat de Barcelona, Barcelona, Espanha. E-mail: jjulioti@yahoo.com.br.

${ }^{9}$ Programa de mestrado e doutorado em Ciências da Reabilitação, Universidade Nove de Julho (UNINOVE), São

Paulo (SP), Brasil. E-mail: oliveira.Ivf@uninove.br.
} 